\title{
Kinetic Monte Carlo simulations unveil synergic effects at work on bifunctional catalysts
}

Hèctor Prats ${ }^{\dagger}$, Sergi Posada-Pérez ${ }^{\dagger}$, José A. Rodriguez ${ }^{\S}$, Ramón Sayós, ${ }^{\dagger}$ Francesc Illas ${ }^{*} \dagger$

'Departament de Ciència de Materials i Química Física \& Institut de Química Teòrica $i$ Computacional (IQTCUB), Universitat de Barcelona, Martí i Franquès 1-11, 08028 Barcelona, Spain.

$\S$ Chemistry Department, Brookhaven National Laboratory, Upton, New York 11973, United States of America.

${ }^{*}$ Corresponding author: Francesc Illas (francesc.illas@ub.edu)

\section{Supporting Figures}

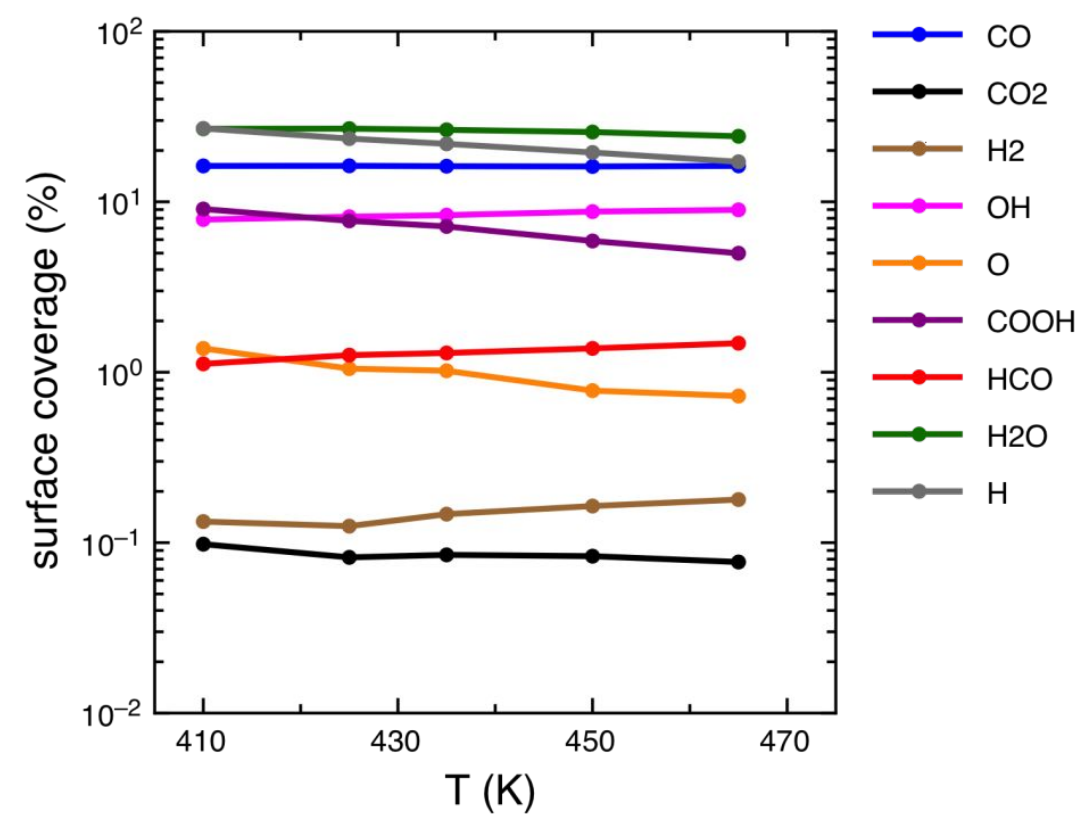

Figure S1. Surface coverage for different adsorbates on $\mathrm{Au}(0.15 \mathrm{ML}) / \mathrm{MoC}$ as a function of reaction temperature $\left(\mathrm{P}_{\mathrm{CO}}=20\right.$ torr, $\mathrm{P}_{\mathrm{H} 2 \mathrm{O}}=10$ torr $)$. 


\section{Supporting Notes}

\section{Supporting Note 1}

Atomic $\mathrm{H}$ is adsorbed on a special hydrogen reservoir site $\left(h\right.$ or $h_{i n}$ ), which has the same energetics as a $t C$ (or $t C_{\text {in }}$ ) site but is exclusively occupied by $\mathrm{H}$ in the $\mathrm{kMC}$ model. The idea of using a special site for $\mathrm{H}$ was proposed by Lausche et al. ${ }^{1}$. This choice is made to work with a more realistic kMC lattice model. A lattice model is a network composed of points -the adsorption sites- and lines describing their connectivity with the neighboring sites. In kMC simulations, the "hard-sphere" model is used, which means that the occupation of a site by an adsorbate excludes other adsorbates from occupying it. However, it has been both experimentally and theoretically shown that hydrogen has negligible interactions with itself and other adsorbates on many surfaces. ${ }^{2,3,4}$ Hence, the use of a "hard-sphere" model might not be appropriate for hydrogen. One strategy for dealing with this problem is to assert that hydrogen adsorbs on a separate set of special sites, which is superimposed on the original lattice. These special hydrogen reservoir sites are connected and available for reaction with adsorbates on all other neighboring sites in the model.

\section{Supporting Note 2}

Formation energies for adsorbates and transition states have been obtained from DFT calculations on the clean $\mathrm{MoC}$ and $\mathrm{Au}(0.25 \mathrm{ML}) / \mathrm{MoC}$ slab models. The $\mathrm{Au}(0.15 \mathrm{ML}) / \mathrm{MoC}$ lattice model has been built as a combination between both systems (see Figure 1). Therefore, the DFT parameters entering the $\mathrm{kMC}$ simulations on the $\mathrm{Au}(0.15 \mathrm{ML}) / \mathrm{MoC}$ model are taken from the DFT calculations of both clean $\mathrm{MoC}$ and $\mathrm{Au}(0.25 \mathrm{ML}) / \mathrm{MoC}$ slab models. Note that in order to model directly the $\mathrm{Au}(0.15$ $\mathrm{ML}) / \mathrm{MoC}$, a large supercell is mandatory, which make practically unaffordable to fill out the reaction scheme by DFT calculations. Hence, in the frontier line between the clean and the interface regions of the $\mathrm{Au}(0.15 \mathrm{ML}) / \mathrm{MoC}$ model, some additional considerations must be performed. For instance, $\mathrm{CO}_{2}$ is a bidentate species that can be adsorbed occupying sites from both regions at the same time

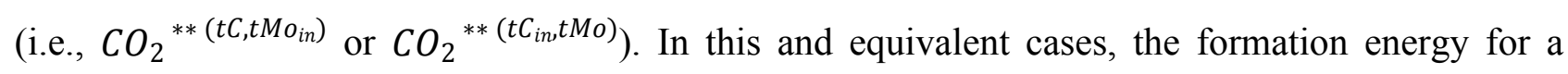
particular configuration is calculated from the average between the formation energies on the clean

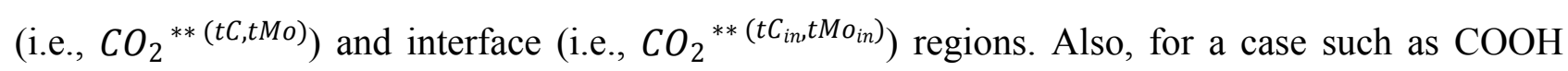
dissociation to $\mathrm{CO}_{2}$ and $\mathrm{H}$ at the frontier line (processes 30 and 31) it is necessary to consider that, while the dissociation barriers for $\mathrm{COOH}^{* *(t C, t M o)}$ and $\mathrm{COOH}^{* *\left(t C_{i n}, t M o_{i n}\right)}$ are different, the energy barrier corresponding to a $\mathrm{COOH}$ adsorbed on the frontier line (i.e., $\mathrm{COOH}^{* *}\left(t C, t M o_{\text {in }}\right)$ or

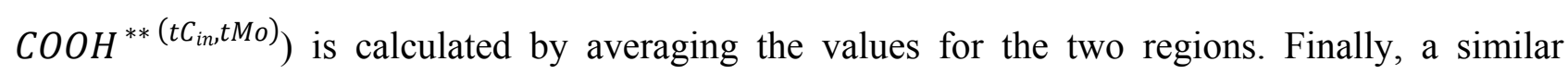


procedure is used for lateral interactions between coadsorbed pairs of adsorbates, one on each side of the frontier line. Consider for instance the $\mathrm{CO}-\mathrm{H}_{2} \mathrm{O}$ repulsion. The repulsion corresponding to a $\mathrm{CO}^{* t C}-\mathrm{H}_{2} \mathrm{O}^{* t M o}$ pair is $0.15 \mathrm{eV}$, whereas the corresponding value for $\mathrm{CO}^{* t C_{\text {in }}}-\mathrm{H}_{2} \mathrm{O}^{* t M o_{\text {in }}}$ is 0.11 $\mathrm{eV}$. Thus, we assumed a lateral interaction of $0.13 \mathrm{eV}$ when they are one on each side of the border (i.e., $\mathrm{CO}^{* t C}-\mathrm{H}_{2} \mathrm{O}^{* t M o_{i n}}$ or $\mathrm{CO}^{* t C_{i n}}-\mathrm{H}_{2} \mathrm{O}^{* t M o}$ ).

\section{Supporting Note 3}

Due to the heterogeneity of adsorption sites and the high number of species involved in our reaction model, we are forced to truncate the cluster expansion to first-nearest-neighbor (1NN) two-body terms. As we are going to operate in a $\mathrm{CO}, \mathrm{H}_{2} \mathrm{O}, \mathrm{OH}, \mathrm{COOH}, \mathrm{O}$ and $\mathrm{H}$ dominated regime, we focused on the interactions of these species with all intermediates. However, interactions between intermediates having a negligible coverage are not considered (i.e., pairwise interaction between two neighboring HCOO species). Overall, we included 38 different one-body terms and 75 different twobody terms, which are listed in Supporting Tables 3 and 4, respectively. One body terms were calculated as the formation energies of the adsorbed species (one DFT calculation for each term), and two-body terms were obtained as the difference between the formation energy of the coadsorbed species and the formation energies of the isolated species (one additional DFT calculation for each term). Hence, a set of 113 DFT calculations was used to fit our cluster expansion. Of course, fitting cluster expansions with longer-range interactions and including additional multi-body terms is likely to improve the quality of the expansion..$^{5,6}$ However, our system involves 7 types of adsorption sites and 11 surface species, where most species can be adsorbed at different adsorption sites. Hence, adding extra parameters to our cluster expansion would involve performing an exorbitant amount of DFT calculations. More importantly, in the view of the reported results reproducing the most salient experimental features, and of the available experimental information, increasing the accuracy of the cluster expansion is not justified.

The set of cluster interactions for the clean $\mathrm{MoC}$ system has been obtained from the full set in the $\mathrm{Au}(0.15 \mathrm{ML}) / \mathrm{MoC}$ system by removing all terms involving adsorption sites from the interface region or the $\mathrm{Au}$ cluster. Likewise, the set of cluster interactions for the $\mathrm{Au}(0.25 \mathrm{ML}) / \mathrm{MoC}$ system is obtained by removing all terms involving adsorption sites from the clean region. 


\section{Supporting Methods}

\section{DFT calculations}

Most of the energy related quantities were taken from previous work ${ }^{7}$ with additional values required to provide a complete description of the overall process obtained using the same computational setup. Thus, periodic DFT calculations were carried out using the Vienna Ab initio Simulation Package $(V A S P),{ }^{8}$ using the Perdew-Burke-Ernzerhof (PBE) exchange-correlation functional. ${ }^{9}$ The threshold for the convergence of the electronic optimization was $10^{-5} \mathrm{eV}$, while the relaxation of the atomic positions was allowed until the forces acting on all the atoms were smaller than $0.01 \mathrm{eV} \AA^{-1}$. The clean $\delta$-MoC $(001)$ model consist of a $\mathrm{R}^{\circ} 5^{\circ}(2 \sqrt{2} \times 2 \sqrt{2})$ supercell containing $8 \mathrm{C}$ and 8 Mo atoms in the surface layer. The $\mathrm{Au} / \mathrm{MoC}$ system was simulated by supporting a $\mathrm{Au}_{4}$ cluster on the $\delta$ MoC(001) surface model described above. This second model represents a system with $\theta_{A u} \sim 0.25$ ML and has been described in detail in previous work. ${ }^{7}$ Thus, the $\mathrm{Au}(0.25 \mathrm{ML}) / \mathrm{MoC}$ notation will used to describe this systems whereas the naked surface will be referred to as clean MoC (see Figure 1, left side). Finally, to avoid interactions between the larger adsorbed species and their periodic replicas, a larger $\mathrm{R} 45^{\circ}(3 \sqrt{2} \times 3 \sqrt{2})$ supercell with a supported $\mathrm{Au}_{4}$ cluster was used to compute the $1 \mathrm{NN}$ pairwise interactions of these adsorbates at the interface region. This larger supercell was also used to compute diffusion barriers of adsorbates from the interface region to the clean region and viceversa, as well as to compute some the energy barrier of the corresponding bimolecular reactions occurring at the interface region. These were not considered in the previous work. For these calculations, a cutoff kinetic energy of $415 \mathrm{eV}$ was used together with a $5 \times 5 \times 1(1 \times 1 \times 1$ for the larger supercell) mesh of $k$-points, selected by means of the Monkhorst-Pack scheme to carry out the numerical integrations in the Brillouin zone. ${ }^{10}$ All energy values include the zero-point energy (ZPE) contribution, which have been calculated by considering both gas phase and adsorbed phase within the harmonic approximation.

\section{Calculation of formation energies}

The reference set for all formation energy values is $\left\{\mathrm{slab}, \mathrm{CO}_{(g)}, \mathrm{H}_{2} \mathrm{O}_{(g)}, \mathrm{H}_{2(g)}\right\}$. The formation energy of adsorbate $i, \mathrm{E}_{\mathrm{i}}^{\mathrm{f}}$ is calculated as:

$$
\mathrm{E}_{\mathrm{i}}^{\mathrm{f}}=\mathrm{U}_{\mathrm{i}}+\text { slab }-\mathrm{U}_{\text {slab }}-\sum_{\mathrm{j}}\left(\mathrm{n}_{\mathrm{j}} \mathrm{R}_{\mathrm{j}}\right)
$$


where $\mathrm{U}_{\mathrm{i}}+$ slab is the raw DFT energy of the slab with adsorbate $i, \mathrm{U}_{\text {slab }}$ is the raw DFT energy of the naked slab, $\mathrm{n}_{\mathrm{j}}$ is the number of atomic species $j$ in $i$, and $\mathrm{R}_{\mathrm{j}}$ is the reference energy of that atomic species, defined in our reference set as

$$
\begin{gathered}
\mathrm{R}_{\mathrm{H}}=\frac{1}{2} \mathrm{U}_{\mathrm{H}_{2(\mathrm{~g})}} \\
\mathrm{R}_{\mathrm{O}}=\mathrm{U}_{\mathrm{H}_{2} \mathrm{O}_{(\mathrm{g})}}-2 \mathrm{R}_{\mathrm{H}} \\
\mathrm{R}_{\mathrm{C}}=\mathrm{U}_{\mathrm{CO}_{(\mathrm{g})}}-\mathrm{R}_{\mathrm{O}}
\end{gathered}
$$

where again $\mathrm{U}_{\mathrm{i}(\mathrm{g})}$ is a raw energy directly taken from the DFT based calculation. Formation energies of all species used in the model, including the ZPE term, are listed in Supporting Table 3.

Since standard GGA functionals do not accurately enough describe the thermochemistry of gas-phase reactions, specially at low temperature, they fail to reproduce the experimental values of equilibrium constant for the reaction in gas-phase. To circumvent this problem, some authors suggest to adjust the formation energies of gas-phase and surface species to match the gas-phase NIST data and then used in the microkinetic models ${ }^{11,12}$ or kMC simulations. ${ }^{13}$ This is obviously a critical issue when simulating closed systems, where the reaction achieves a thermodynamic equilibrium. However, we would argue that these discrepancies are less important when simulating open systems in a nonequilibrium state, as in the case of the present study. Moreover, adjusting the calculated data using experimental information adds a degree of empiricism that, unless strictly necessary, should be avoided in a first principles oriented study as this will reduce the predictive power of the overall approach Hence, we have decided not to adjust the DFT-calculated formation energies to match the experimental data. This view is also supported by the large body of literature comparing kMC simulations based on non-adjusted DFT calculations at the GGA level with experimental values, and is reinforced by the excellent agreement between the present $\mathrm{kMC}$ simulations and the available experimental data. 


\section{Kinetic Monte Carlo simulations}

The time evolution of a system at the molecular level can be simulated by the kMC method, in which all the possible reactions or processes that can occur are taken into account and have an associated transition probability. In the present study, we use the recently developed graph-theoretical kMC approach $^{14}$ coupled with cluster expansion Hamiltonians ${ }^{15,16}$ for the adlayer energetics by means of ZACROS code (version 1.01). ${ }^{14,15}$ This code has been extensively validated in the literature for simulating complex heterogeneously catalyzed reactions, ${ }^{17,18}$ making it one of the most popular kMC codes. Therefore, no validation of this $\mathrm{kMC}$ code is needed on this study. As in previous kMC schemes, a simulation is initialized with a given lattice configuration (in our case an empty lattice), and a list is generated containing all the possible lattice processes for the given configuration. Then, the algorithm enters a loop until the stop conditions are fulfilled. At each step the most imminent process in the queue, defined as the one with the smallest time of occurrence according to the firstreaction method, ${ }^{19}$ is executed. Finally, a stochastic trajectory is obtained containing all the information about the lattice configuration as well as the number of gas-phase molecules produced or consumed at every time step. This trajectory can be analysed to get information such as the equilibrium surface coverage, the final $\mathrm{CO}_{2}$ and/or $\mathrm{H}_{2}$ production or the contribution of each possible reaction channel.

The present kMC simulations describe an experiment with a fresh mixture of $\mathrm{CO}$ and $\mathrm{H}_{2} \mathrm{O}$ as reactant with $\mathrm{P}_{\mathrm{CO}}=20$ torr and $\mathrm{P}_{\mathrm{H} 2 \mathrm{O}}=10$ torr continuously impinging on an empty thermalized clean $\mathrm{MoC}, \mathrm{Au}(0.25 \mathrm{ML}) / \mathrm{MoC}$ or $\mathrm{Au}(0.15 \mathrm{ML}) / \mathrm{MoC}$ surface where WGSR takes place and the final gas $\mathrm{CO}_{2}$ and $\mathrm{H}_{2}$ molecules produced desorb and leave the surface region. The reaction conditions were chosen to allow direct comparison with the experiment. ${ }^{7}$ Each kMC simulation is first run until a steady-state is achieved, assessed by the temporal convergence of coverage and TOFs and neglecting the small fluctuations resulting from the stochastic nature of the simulation. At this point, the production stage starts which runs for a production of at least $70.000 \mathrm{H}_{2}$ molecules. The overall macroscopic properties reported in the manuscript correspond to an average from 5 independent kMC simulations over the production stages. The kMC simulations differ from each other in the sequence of random numbers used only.

\section{Calculation of transition probabilities}

The transition probability of an elementary process in kMC simulations specifies the number of times this process occurs per site and time unit. For a surface reaction of the type $A+B \rightarrow C$, the partition functions of all species have only vibrational components, and the transition probability can be calculated from $\operatorname{TST}^{20}$ applied to surface reactions ${ }^{21}$ as: 


$$
\mathrm{w}_{\text {surf. }}=\frac{\mathrm{k}_{\mathrm{b}} \mathrm{T} \quad \mathrm{Q}_{\mathrm{vib}}^{\neq}}{\mathrm{h} \mathrm{Q}_{\mathrm{vib}, \mathrm{A}} \cdot \mathrm{Q}_{\mathrm{vib}, \mathrm{B}}} \exp \left[-\frac{\Delta \mathrm{E}^{\neq}(\sigma)}{\mathrm{k}_{\mathrm{b}} \mathrm{T}}\right]
$$

where $Q_{\text {vib,i }}$ and $Q_{\text {vib }}^{\neq}$are the vibrational partition functions of adsorbed species $i$ and of the transition state structure, respectively, and $\Delta \mathrm{E}^{\neq}(\sigma)$ is the configuration-dependent energy barrier (including the zero-point energy correction). This last term is calculated from the energy barrier at zero-coverage limit and the lateral interactions between adsorbates and make use of Brønsted-Evans-Polanyi (BEP) relationships ${ }^{22}$ as done when coupling $\mathrm{kMC}$ with cluster expansion models for the adlayer energetics. Regarding adsorption and desorption processes, $\mathrm{CO}$ and $\mathrm{H}_{2} \mathrm{O}$ adsorptions on the $\mathrm{MoC}$ and $\mathrm{Au} / \mathrm{MoC}$ are assumed to be not activated $\left(\mathrm{E}_{\mathrm{ads}}^{\neq}=0 \mathrm{eV}\right)$. In that case, one assumes an early two-dimensional (2D) gas-like transition state and thus the corresponding transition probabilities for adsorption and desorption simplify to: ${ }^{14}$

$$
\begin{gathered}
\mathrm{w}_{\mathrm{ads}, i}^{\text {non }- \text { act. }}=\mathrm{S} \frac{\mathrm{P}_{i} \mathrm{~A}}{\sqrt{2 \pi \mathrm{m}_{i} \mathrm{k}_{\mathrm{B}} \mathrm{T}}} \\
\mathrm{w}_{\text {des }, i}^{\text {non }- \text { act. }}=\mathrm{S} \frac{\mathrm{k}_{\mathrm{B}} \mathrm{TQ} \mathrm{Qtrans}_{\mathrm{t}, i_{(\mathrm{g})}} \cdot \mathrm{Q}_{\mathrm{rot}, i_{(\mathrm{g})}} \cdot \mathrm{Q}_{\mathrm{vib}, i_{(\mathrm{g})}}}{\mathrm{h}} \mathrm{e}^{\Delta E_{a d s}(\sigma) / \mathrm{k}_{\mathrm{B}} \mathrm{T}} \\
\mathrm{Q}_{\mathrm{vib}, i}
\end{gathered}
$$

where $\mathrm{P}_{i}$ is the partial pressure of gas species $i$, A is the area of a single adsorption site (i.e., $4.32 \AA^{2}$ ), $\mathrm{m}_{i}$ is the molecular mass of species $i, \mathrm{k}_{\mathrm{B}}$ and $\mathrm{T}$ are the Boltzmann constant and working temperature, respectively, $S$ is the sticking coefficient ${ }^{20}$ here assumed as $S=1, Q_{\text {rot }, i_{(\mathrm{g})}}$ and $Q_{\mathrm{vib}, i_{(\mathrm{g})}}$ are the rotational and vibrational gas-phase partition functions, respectively, $Q_{v i b, i}$ is the vibrational partition function for adsorbate $i, \Delta E_{a d s}(\sigma)$ is the configuration-dependent adsorption energy, and finally $Q_{\operatorname{trans} 2 \mathrm{D}, i_{(\mathrm{g})}}$ is the $2 \mathrm{D}$ translational partition function over the adsorption site:

$$
Q_{\text {trans } 2 \mathrm{D}, i_{(\mathrm{g})}}=\mathrm{A} \frac{2 \pi \mathrm{m}_{i} \mathrm{k}_{\mathrm{B}} \mathrm{T}}{\mathrm{h}^{2}}
$$

Equations (6) and (7) ensure that description of the free energy landscape for the forward and reverse process between gas-phase and adsorbed state is done thermodynamically consistently. ${ }^{23}$

\section{Scaling fast processes}

The present reaction model contains processes with very dissimilar transition probabilities. The fastest ones are usually diffusion processes with energy barriers lower than $0.25 \mathrm{eV}$, implying that they would dominate and extremely long $\mathrm{kMC}$ simulations would be required to observe some evolution of the overall chemical process. The solution is to reduce the rate transition probabilities of the fast quasi-equilibrated processes to enable more frequent execution of the slower reactive surface processes. After the reduction, these processes must remain quasi-equilibrated and fast, but in an 
order of magnitude closer to that of the other slower processes. A sophisticated solution is to use accelerated $\mathrm{kMC}$ algorithms, as the ones developed by Chaterjee et al. ${ }^{24}$ or by Dybeck et al. ${ }^{25}$. However, these algorithms are not implemented in Zacros 1.01 code. We have used a more straightforward solution called "manually scaling", that consists on multiply the transition probabilities of fast processes (in both forward and backward directions) by some scaling factor $\alpha<1$. This solution has been successfully applied in many kMC studies. ${ }^{26,27,28}$ Specifically, we have reduced the transition probabilities of 12 diffusion processes, one adsorption process, and 2 reaction processes, with scaling factors ranging from $10^{-1}$ to $10^{-7}$ :

\begin{tabular}{|c|c|c|}
\hline ID & Process & $\log \alpha$ \\
\hline 3 & $\mathrm{H}_{2} \mathrm{O}_{(g)}+*_{t A u} \leftrightarrow \mathrm{H}_{2} \mathrm{O}^{* t A u}$ & -1 \\
\hline 17 & 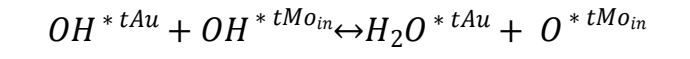 & -1 \\
\hline 24 & $C O^{* t C}+O H^{*(t C, t M o)} \leftrightarrow \mathrm{COOH}^{* *(t C, t M o)}+*{ }_{t C}$ & -3 \\
\hline 58 & $H^{* h}+*_{h} \leftrightarrow *{ }_{h}+H^{* h}$ & -6 \\
\hline 59 & $H^{* h}+*_{h_{i n}} \leftrightarrow *_{h}+H^{* h_{i n}}$ & -6 \\
\hline 60 & $H^{* h_{i n}}+*_{h_{i n}} \leftrightarrow *_{h_{i n}}+H^{* h_{i n}}$ & -7 \\
\hline 61 & $O^{* t C}+* t M o \leftrightarrow * t C+O * t M o$ & -1 \\
\hline 62 & $O^{* t C_{i n}}+*{ }_{t M o_{i n}} \leftrightarrow *{ }_{t} C_{i n}+O^{* t M o_{i n}}$ & -3 \\
\hline 64 & $O^{* t C_{i n}}+*_{t M o} \leftrightarrow *{ }_{t C_{i n}}+O * t M o$ & -1 \\
\hline 68 & $O H^{* t A u}+*_{t M o_{i n}} \leftrightarrow *_{t A u}+O H^{* t M o_{\text {in }}}$ & -1 \\
\hline 69 & $\mathrm{H}_{2} \mathrm{O}^{* t A u}+*_{t M o_{i n}} \leftrightarrow *_{t A u}+\mathrm{H}_{2} \mathrm{O}^{* t M o_{i n}}$ & -4 \\
\hline 70 & $C O^{* t A u}+*_{t C_{i n}} \leftrightarrow *_{t A u}+C O^{* t C_{i n}}$ & -3 \\
\hline 71 & $C O^{* t M o}+*{ }_{t C} \leftrightarrow *{ }_{t M o}+C O * t C$ & -2 \\
\hline 72 & $C O^{* t M o_{i n}}+*_{t C_{i n}} \leftrightarrow *_{t M o_{i n}}+C O^{* t C_{i n}}$ & -2 \\
\hline 73 & $C O^{* t M o}+*_{t C_{i n}} \leftrightarrow *_{t M o}+C O^{* t C_{i n}}$ & -5 \\
\hline
\end{tabular}

We have ensured that, after this reduction, the scaled processes are still fast and quasi-equilibrated. The kMC simulations takes several weeks to complete even after the pre-factor scaling. Hence, to determine the TOFs and coverage before the scaling becomes unfeasible. However, to estimate the changes in the TOF and coverage due to the manually scaling, we have performed an additional set of $\mathrm{kMC}$ simulations where the pre-factors for some scaled processes have been multiplied by a factor of 10. The equilibrium coverage values for the different surface species do not change after this increase in the pre-factor. However, small changes in the TOF are observed:

Processes (ID)

Adsorption and reaction $(3,17,24)$

$\mathrm{H}$ and $\mathrm{OH}$ diffusion $(58,59,60,68)$

$\mathrm{O}$ and $\mathrm{H}_{2} \mathrm{O}$ diffusion $(61,62,64,69)$

$\mathrm{CO}$ diffusion $(70,71,72,73)$

\section{Relative increase on the TOF}

$-3 \%$

$+8 \%$

$+1 \%$

$+24 \%$ 
Although the manually scaling of the selected adsorption and reaction processes and the diffusion of $\mathrm{H}, \mathrm{OH}, \mathrm{O}$ and $\mathrm{H}_{2} \mathrm{O}$ species have no effect on the coverage and almost negligible effect on the calculated TOF, the scaling of the diffusion of CO species does have a non-negligible impact on the calculated TOF. A less drastic scaling for these processes would have been more accurate, although at the expense of increasing the computational cost of the $\mathrm{kMC}$ simulations. Note that, as stated in the manuscript, the main goal of this work is to unravel the origin of the observed synergic effect and the individual role of each region of the catalyst rather than reproducing exactly the experimental TOF of such a complex system. Our calculated TOF on the $\mathrm{Au}(0.15 \mathrm{ML}) / \mathrm{MoC}$ system is 7.7 and 4.3 times higher than the calculated TOFs for the clean $\mathrm{MoC}$ and $\mathrm{Au}(0.25 \mathrm{ML}) / \mathrm{MoC}$ surfaces, respectively. This is in agreement with the experimental values, and obviously is not a consequence of the manually scaling. Hence, even in the presence of these small variations in the overall TOF due to $\mathrm{CO}$ diffusion scaling, the overall conclusions are not affected.

\section{Sensitivity analysis}

A quantitative answer to how much the $\mathrm{kMC}$ results depend on the DFT calculations requires a full sensitivity analysis, by calculating for instance the Capmbell's Degree of Rate Control (DRC), ${ }^{29}$ which ranges from -1 to 1 . The DRC for a given process equals the relative increase in the TOF per relative increase in the rate constant for that process. Hence, small modifications on the DFT computed energy barrier of processes having a DRC near 1 or -1 have a significant impact on the $\mathrm{kMC}$ results, while for processes having a DRC near 0 these modifications won't have any impact at all. In mean-field approximation (MFA) models, this kind of analysis is straightforward. However, in $\mathrm{kMC}$ framework this analysis implies running a set of very long $\mathrm{kMC}$ simulations with different random seeds for each elementary step. We have performed this kind of sensitivity analysis in previous kMC studies involving simpler systems. However, the huge set of elementary processes included in the present study makes this kind of analysis too expensive. Fortunately, when a system involves many different competing processes and several reaction routes, the DRC of the elementary steps should be small, since there is not usually a single determining step acting as a bottleneck. This is the case of the WGSR mechanism on the $\mathrm{Au} / \mathrm{MoC}$ system. In fact, we have performed a sensitivity analysis on a small set of eight processes, selected on the basis of their potential impact. This small set includes water dissociation, $\mathrm{COOH}$ formation, and $\mathrm{COOH}$ reaction by $\mathrm{OH}$ on several regions of the catalyst. In this analysis, both the forward and reverse transition probabilities of the selected process were increased by a $10 \%$. We have found that the absolute value of the DRC is always lower than 0.15 indicating that small changes $(<0.05 \mathrm{eV})$ in the relevant energy barriers will not have a significant impact on the conclusions reached by the present kMC simulations. 


\section{Supporting Tables}

All elementary steps included in the reaction model are listed below. Gas-phase molecules are denoted with $(g)$, and free top-C/top-Mo/top-Au/H-reservoir sites are denoted by ${ }^{*} t C / t M o / t A u / h$ respectively. The subscript in means that the site belongs to the interface region.

Table S1. Reaction (non-diffusive) steps on $\mathrm{Au}(0.15 \mathrm{ML}) / \mathrm{MoC}$ and their corresponding energy barriers, including the ZPE term.

ID$$
1
$$

\section{Process}

$$
\begin{aligned}
& \mathrm{H}_{2} \mathrm{O}_{(\mathrm{g})}+* t M o \leftrightarrow \mathrm{H}_{2} \mathrm{O} * t M o \\
& \mathrm{H}_{2} \mathrm{O}_{(\mathrm{g})}+* \mathrm{tMo}_{\text {in }} \leftrightarrow \mathrm{H}_{2} \mathrm{O} * t M o_{\text {in }} \\
& \mathrm{H}_{2} \mathrm{O}_{(\mathrm{g})}+*_{t A u} \leftrightarrow \mathrm{H}_{2} \mathrm{O} * t A u \\
& \mathrm{CO}_{(g)}+* t C \leftrightarrow C O * t C \\
& \mathrm{CO}_{(g)}+*_{t M o} \leftrightarrow C \mathrm{O}^{* t M o} \\
& C O_{(g)}+*_{t C_{i n}} \leftrightarrow C O^{* t C_{i n}} \\
& \mathrm{CO}_{(g)}+*_{t M o_{i n}} \leftrightarrow \mathrm{CO} * t \mathrm{Mo}_{\text {in }} \\
& C O_{(g)}+* t A u \leftrightarrow C O * t A u \\
& \mathrm{H}_{2} \mathrm{O}^{* t M o}+* t C+*{ }_{h} \leftrightarrow O H^{* *}(t C, t M o)+H^{* h} \\
& \mathrm{H}_{2} \mathrm{O}^{* t M o_{i n}}+* h_{i n} \leftrightarrow O H^{* t M o_{i n}}+H^{* h_{\text {in }}} \\
& \mathrm{H}_{2} \mathrm{O}^{* t A u}+*{ }_{h_{i n}} \leftrightarrow O H^{* t A u}+H^{* h_{\text {in }}} \\
& O H^{* *(t C, t M o)}+*{ }_{h} \leftrightarrow O^{* t M o}+H^{* h}+* t C \\
& O H^{* *(t C, t M o)}+*_{h} \leftrightarrow O^{* t C}+H^{* h}+* t M o \\
& O H^{* t A u}+* h_{i n} \leftrightarrow O^{* t A u}+H^{* h_{\text {in }}} \\
& O H^{* *(t C, t M o)}+O H^{* *(t C, t M o)} \leftrightarrow O^{* t C}+H_{2} O^{* t M o}+* t C+* t M o \\
& O H^{* t M o_{i n}}+\mathrm{OH}^{* t M o_{i n} \leftrightarrow \mathrm{H}_{2} \mathrm{O}^{* t M o_{i n}}+\mathrm{O}^{* t M o_{\text {in }}}}
\end{aligned}
$$

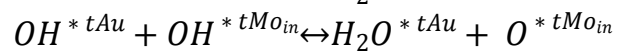

$$
\begin{aligned}
& C O^{* t C}+* t M o \leftrightarrow C^{* t C}+O * t M o \\
& C \mathrm{O}^{* t C}+\mathrm{O}^{* t M o} \leftrightarrow \mathrm{CO}_{2}{ }^{* *}(t C, t M o) \\
& C O^{* t C_{i n}}+O^{* t M o_{i n} \leftrightarrow C O_{2}}{ }^{* *}\left(t C_{i n}, t M o_{i n}\right) \\
& C O^{* t C_{\text {in }}}+O^{* t A u}+* t M o_{i n} \leftrightarrow C_{2}{ }^{* *}\left(t C_{i n}, t M o_{i n}\right)+* t A u \\
& C O^{* t C_{i n}}+O^{* t A u} \leftrightarrow * t C_{i n}+C O_{2} * t A u \\
& \mathrm{CO}^{* t C_{i n}}+\mathrm{O}^{* t M o} \leftrightarrow \mathrm{CO}_{2}{ }^{* *}\left(t C_{i n}, t M o\right) \\
& \mathrm{CO}^{* t C}+\mathrm{OH}^{*(t C, t M o)} \leftrightarrow \mathrm{COOH}^{* *(t C, t M o)}+* t C \\
& \mathrm{CO}^{* t C_{i n}}+\mathrm{OH}^{* t M o_{i n} \leftrightarrow \mathrm{COOH}^{* *}\left(t C_{i n}, t M o_{i n}\right)} \\
& \mathrm{CO}^{* t C}+\mathrm{OH}^{* t M o_{\text {in }} \leftrightarrow \mathrm{COOH}^{* *}\left(t C, t M o_{i n}\right)} \\
& C O^{* t C_{i n}}+\mathrm{OH}^{*(t C, t M o)} \leftrightarrow \mathrm{COOH}^{* *\left(t C_{i n}, t M o\right)}+*_{t C} \\
& \mathrm{COOH}^{* *(t C, t M o)}+*{ }_{h} \leftrightarrow \mathrm{CO}_{2}{ }^{* *}(t C, t M o)+H^{* h} \\
& \mathrm{COOH}^{* *\left(t C_{i n}, t M o_{i n}\right)}+* h_{i n} \leftrightarrow \mathrm{CO}_{2}{ }^{* *\left(t C_{i n}, t M o_{i n}\right)}+H^{* h_{i n}} \\
& \mathrm{COOH}^{* *\left(t C, t M o_{\text {in }}\right)}+*_{h} \leftrightarrow \mathrm{CO}_{2}{ }^{* *\left(t C, t M o_{i n}\right)}+H^{* h}
\end{aligned}
$$

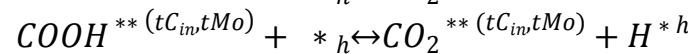

$$
\begin{aligned}
& \mathrm{COOH}^{* *(t C, t M o)}+\mathrm{OH}^{*(t C, t M o)} \leftrightarrow \mathrm{CO}_{2}{ }^{* *(t C, t M o)}+\mathrm{H}_{2} \mathrm{O}^{* t M o}+* t C \\
& \mathrm{COOH}^{* *\left(t C_{i n}, t M o_{i n}\right)}+\mathrm{OH}^{* t M o_{\text {in }} \leftrightarrow \mathrm{CO}_{2}}{ }^{* *\left(t C_{i n}, t M o_{i n}\right)}+\mathrm{H}_{2} \mathrm{O}^{* t M o_{i n}} \\
& \mathrm{COOH}^{* *\left(t C_{i n}, t M o_{i n}\right)}+\mathrm{OH}^{* t A u} \leftrightarrow \mathrm{CO}_{2}{ }^{* *\left(t C_{i n}, t M o_{i n}\right)}+\mathrm{H}_{2} \mathrm{O} * t \mathrm{Au} \\
& \mathrm{COOH}^{* *\left(t C, t M o_{i n}\right)}+\mathrm{OH}^{*(t C, t M o)} \leftrightarrow \mathrm{CO}_{2}{ }^{* *\left(t C, t M o_{i n}\right)}+\mathrm{H}_{2} \mathrm{O}^{* t M o}+* t C
\end{aligned}
$$

$\Delta \mathbf{E}^{\neq}$

(eV)

$0.00 \quad 7$

$0.00 \quad 7$

$0.00 \quad 7$

$0.00 \quad 7$

$0.00 \quad 7$

$0.00 \quad 7$

$0.00 \quad 7$

$0.00 \quad 7$

$0.53 \quad 7$

$\begin{array}{ll}0.79 & 7\end{array}$

$1.23 \quad 7$

$1.56 \quad 7$

$1.56 \quad 7$

1.64 This work

$2.22 \quad 7$

0.447

$0.44 \quad 7$

1.79 This work

$1.52 \quad 7$

$0.09 \quad 7$

$0.09 \quad 7$

$0.09 \quad 7$

$1.52 \quad 7$

0.51 This work

$0.62 \quad 7$

0.56 This work

0.56 This work

$0.27 \quad 7$

0.97 This work

0.62 This work

0.62 This work

0.37 This work

0.22 This work

0.89 This work

0.29 This work 


36
37
38
39
40
41
42
43
44
45
46
47
48
49
50
51
52
53
54
55
56
57

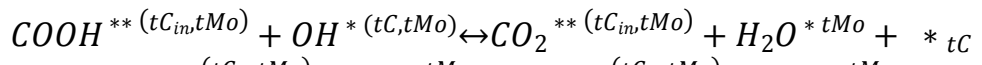

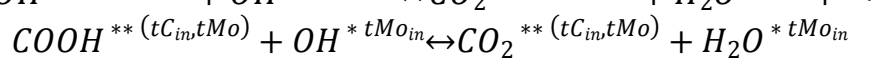

$$
\begin{aligned}
& C O^{* t C}+H^{* h}+* t M o \leftrightarrow H C O^{* *(t C, t M o)}+*_{h} \\
& \mathrm{HCO}^{* *}(t C, t M o)+\mathrm{O}^{* t M o} \leftrightarrow H C O O^{* * *}(t C, t M o, t M o) \\
& \mathrm{HCOO}^{* * *}(t C, t \mathrm{Mo}, t \mathrm{Mo})+* \mathrm{~h}^{\leftrightarrow} \mathrm{CO}_{2}{ }^{* *}(t C, t M o)+{ }_{t M o}+H^{* h} \\
& H^{* h}+H^{* h}+* t C \leftrightarrow H_{2}{ }^{* t C}+2 * h \\
& H^{* h}+H^{* h}+* t M o \leftrightarrow H_{2}{ }^{* t M o}+2 * h \\
& H^{* h_{i n}}+H^{* h_{i n}}+*_{t C_{i n}} \leftrightarrow H_{2}{ }^{* t C_{i n}}+2 * h_{\text {in }} \\
& H^{* h_{i n}}+H^{* h_{i n}}+*_{t M o_{i n}} \leftrightarrow H_{2}{ }^{* t M o_{i n}}+2 * h_{i n} \\
& H^{* h_{i n}}+H^{* h_{i n}}+*_{t A u} \leftrightarrow H_{2}{ }^{* t A u}+2 * h_{i n} \\
& H^{* h}+H^{* h_{i n}}+* t C_{i n} \leftrightarrow H_{2}{ }^{* t C_{i n}}+2 * h_{i n} \\
& H^{* h}+H^{* h_{i n}}+*_{t M o_{i n}} \leftrightarrow H_{2}{ }^{* t M o_{i n}}+2 * h_{i n} \\
& \mathrm{H}_{2}{ }^{* t C} \longrightarrow \mathrm{H}_{2(\mathrm{~g})}+{ }^{*} t \mathrm{C} \\
& \mathrm{H}_{2}{ }^{* t M o} \longrightarrow \mathrm{H}_{2(\mathrm{~g})}+{ }^{*}{ }_{t M o} \\
& \mathrm{H}_{2}{ }^{*} \mathrm{C}_{\text {in }} \longrightarrow \mathrm{H}_{2(\mathrm{~g})}+{ }^{*} t C_{\text {in }} \\
& \mathrm{H}_{2}{ }^{* t M o_{\text {in }}} \longrightarrow \mathrm{H}_{2(\mathrm{~g})}+*{ }^{*} \mathrm{tMo} o_{\text {in }} \\
& \mathrm{H}_{2}{ }^{*} \mathrm{tAu} \longrightarrow \mathrm{H}_{2(\mathrm{~g})}+{ }^{*} t \mathrm{tAu} \\
& \mathrm{CO}_{2}{ }^{* *}(t C, t M o) \rightarrow \mathrm{CO}_{2(g)}+*{ }_{t C}+*{ }_{t M o} \\
& \mathrm{CO}_{2}{ }^{* *}\left(t C_{i n}, \mathrm{Mo}_{\text {in }}\right) \rightarrow \mathrm{CO}_{2(\mathrm{~g})}+* t C_{\text {in }}+* t M o_{\text {in }} \\
& \mathrm{CO}_{2} * t A u \rightarrow \mathrm{CO}_{2(\mathrm{~g})}+*{ }_{t A u} \\
& \mathrm{CO}_{2}{ }^{* *\left(t C, t M o_{i n}\right)} \rightarrow \mathrm{CO}_{2(g)}+{ }_{t C}+{ }_{t}{ }_{t M o} \text { in } \\
& \mathrm{CO}_{2}{ }^{* *\left(t C_{i n}, t M o\right)} \rightarrow \mathrm{CO}_{2(g)}+{ }^{*}{ }_{t C_{i n}}+*_{t M o}
\end{aligned}
$$

0.29 This work

0.29 This work

$0.79 \quad 7$

$2.02 \quad 7$

$1.94 \quad 7$

$0.75 \quad 7$

$0.75 \quad 7$

$0.79 \quad 7$

$0.79 \quad 7$

0.79 This work

0.77 This work

0.77 This work

$0.45 \quad 7$

0.46 This work

0.05 This work

0.05 This work

$0.05 \quad 7$

$0.82 \quad 7$

0.08 This work

$0.08 \quad 7$

0.45 This work

0.45 This work

Table S2. Diffusion steps on $\mathrm{Au}(0.15 \mathrm{ML}) / \mathrm{MoC}$ and their corresponding energy barriers, including the ZPE term.

ID

58

59

60

61

62

63

64

65

66

67

68

69

70

71

72

73
Process

$$
\begin{aligned}
& H^{* h}+*{ }_{h} \leftrightarrow *{ }_{h}+H^{* h} \\
& H^{* h}+*{ }_{h_{i n}} \leftrightarrow *{ }_{h}+H^{* h_{i n}} \\
& H^{* h_{\text {in }}}+*_{h_{\text {in }}} \leftrightarrow *{ }^{*} h_{\text {in }}+H^{* h_{\text {in }}} \\
& O^{* t C}+* t M o \leftrightarrow * t C+O^{* t M o} \\
& O^{* t C_{i n}}+*{ }_{t M o_{i n}} \leftrightarrow * t C_{\text {in }}+O^{* t M o_{i n}} \\
& O^{* t C}+*{ }_{t M o_{i n}} \leftrightarrow * t C+O * t M o_{i n} \\
& O^{* t C_{i n}}+* t M o \leftrightarrow * t C_{i n}+O * t M o \\
& O^{* t A u}+* t M o_{\text {in }} \leftrightarrow * t A u+O * t M o_{\text {in }} \\
& O * t A u+* t C_{i n} \leftrightarrow * t A u+O * t C_{\text {in }} \\
& O H^{* t M o_{i n}}+* t C+* t M o \leftrightarrow O H^{* *}(t C, t M o)+* t M o_{\text {in }} \\
& O H^{* t A u}+*_{t M o_{i n}} \leftrightarrow *_{t A u}+O H^{* t M o_{\text {in }}} \\
& \mathrm{H}_{2} \mathrm{O} * t A u+*_{t M o_{\text {in }}} \leftrightarrow *_{t A u}+\mathrm{H}_{2} \mathrm{O} * t M o_{\text {in }} \\
& C O * t A u+*{ }_{t C} \leftrightarrow *{ }_{i n} \text { tAu }+C O * t C_{\text {in }} \\
& C O * t M o+* t C \leftrightarrow *{ }_{t M o}+C O * t C \\
& C O^{* t M o_{i n}}+* t C_{i n} \leftrightarrow * t M o_{i n}+C O * t C_{i n} \\
& C O^{* t M o}+* t C_{i n} \leftrightarrow *{ }_{t M o}+C O * t C_{i n}
\end{aligned}
$$

$\Delta \mathbf{E}^{\neq} \quad$ Ref.

(eV)

0.25 This work

0.20 This work

0.14 This work

0.76 This work

0.25 This work

1.10 This work

0.25 This work

0.25 This work

0.25 This work

0.28 This work

0.51 This work

0.23 This work

0.33 This work

0.12 This work

0.12 This work

0.12 This work 
Table S3. Formation energy values, including the ZPE term, for all the species included on the $\mathrm{Au}(0.15 \mathrm{ML}) / \mathrm{MoC}$ model. They correspond to the one-body terms in the cluster expansion model.

\begin{tabular}{|c|c|}
\hline Species & $\begin{array}{c}\text { Formation energy } \\
(\mathrm{eV})\end{array}$ \\
\hline $\mathrm{H}_{2} \mathrm{O}_{(g)}$ & 0.00 \\
\hline $\mathrm{CO}_{(\mathrm{g})}$ & 0.00 \\
\hline$H_{2(g)}$ & 0.00 \\
\hline $\mathrm{CO}_{2(\mathrm{~g})}$ & -0.93 \\
\hline $\mathrm{CO}^{*} \mathrm{tC}$ & -1.90 \\
\hline$C O^{* t M o}$ & -1.07 \\
\hline$C O^{* t C_{i n}}$ & -1.13 \\
\hline$C O^{* t M o_{i n}}$ & -0.48 \\
\hline$C O^{* t A u}$ & -1.16 \\
\hline $\mathrm{H}_{2} \mathrm{O} * t M o$ & -0.77 \\
\hline $\mathrm{H}_{2} \mathrm{O} * t M o_{i n}$ & -0.36 \\
\hline $\mathrm{H}_{2} \mathrm{O} * t A u$ & -0.27 \\
\hline $\mathrm{CO}_{2}{ }^{* *(t C, t M o)}$ & -1.74 \\
\hline$C \mathrm{O}_{2}{ }^{* *\left(t C_{i n}, t M o_{i n}\right)}$ & -0.84 \\
\hline $\mathrm{CO}_{2}{ }^{* *\left(t C, t M o_{i n}\right)}$ & -1.29 \\
\hline $\mathrm{CO}_{2}{ }^{* *\left(t C_{i n}, t M o\right)}$ & -1.29 \\
\hline $\mathrm{CO}_{2} * t \mathrm{Au}$ & -0.84 \\
\hline$H_{2}{ }^{* t C}$ & -0.45 \\
\hline $\mathrm{H}_{2}{ }^{* t M o}$ & -0.45 \\
\hline $\mathrm{H}_{2} * t C_{\text {in }}$ & -0.05 \\
\hline $\mathrm{H}_{2}{ }^{* t M o_{\text {in }}}$ & -0.05 \\
\hline$O H^{* *(t C, t M o)}$ & -0.86 \\
\hline$O H^{* t M o_{i n}}$ & -0.10 \\
\hline$O H^{* t A u}$ & -0.08 \\
\hline$H^{* h}$ & -0.30 \\
\hline$H^{* h_{i n}}$ & -0.30 \\
\hline$O * t C$ & -0.51 \\
\hline$O * t M o$ & 0.05 \\
\hline$O^{* t C_{i n}}$ & 0.35 \\
\hline$O^{* t M o_{i n}}$ & 0.44 \\
\hline$O^{* t A u}$ & 1.24 \\
\hline $\mathrm{COOH}^{* *}(t C, t \mathrm{Mo})$ & -1.56 \\
\hline $\mathrm{COOH}^{* *}\left(t C_{i n}, t M o_{i n}\right)$ & -1.30 \\
\hline $\mathrm{COOH}^{* *\left(t C, t M o_{\text {in }}\right)}$ & -1.43 \\
\hline$C O O H^{* *}\left(t C_{i n}, t M o\right)$ & -1.43 \\
\hline$H C O^{* *}(t C, t M o)$ & -2.09 \\
\hline $\mathrm{HCOO}^{* * *}(t C, t M o, t M o)$ & -2.76 \\
\hline$C^{* t C}$ & -1.43 \\
\hline
\end{tabular}


Table S4. Pairwise lateral interaction values, including the ZPE term, involved on the $\mathrm{Au}(0.15$ $\mathrm{ML}$ )/MoC model. They correspond to the two-body terms in the cluster expansion model.

\begin{tabular}{|c|c|}
\hline Coadsorbed species & $\begin{array}{c}\text { Lateral interaction } \\
(\mathrm{eV})\end{array}$ \\
\hline$O H^{* *}(t C, t M o)-H^{* h}$ & -0.04 \\
\hline$O H^{* t M o_{i n}}-H^{* h_{i n}}$ & 0.08 \\
\hline$O H^{* t M o_{i n}}-H^{* h}$ & 0.02 \\
\hline$O H^{* t A u}-H^{* h_{i n}}$ & 0.18 \\
\hline$O H^{* *(t C, t M o)}-O^{* t C}$ & 0.02 \\
\hline$O H^{* *}(t C, t M o)-O^{* t M o}$ & 0.02 \\
\hline$O H^{* t M o_{\text {in }}}-O^{* t C}$ & 0.02 \\
\hline$O H^{* t M o_{i n}}-O^{* t C_{i n}}$ & 0.02 \\
\hline$O^{* t C}-O^{* t M o}$ & 0.03 \\
\hline$O^{* t M o}-H^{* h}$ & 0.00 \\
\hline$O^{* t C}-H^{* h}$ & 0.00 \\
\hline$O H^{* *}(t C, t M o)-O H^{* *}(t C, t M o)$ & 0.22 \\
\hline$O H^{* t M o_{i n}}-O H^{* t M o_{i n}}$ & 0.22 \\
\hline$O H^{* *(t C, t M o)}-O H^{* t M o_{i n}}$ & 0.22 \\
\hline$O H^{* t A u}-O H^{* t M o_{i n}}$ & 0.08 \\
\hline$O H^{* t A u}-O H^{* t A u}$ & 0.08 \\
\hline$O H^{* *}(t C, t M o)-H_{2} O^{* t M o}$ & 0.04 \\
\hline$O H^{* *(t C, t M o)}-H_{2} O^{* t M o_{i n}}$ & 0.04 \\
\hline$O H^{* t M o_{i n}}-H_{2} O^{* t A u}$ & 0.05 \\
\hline$O H^{* t A u}-H_{2} O^{* t M o_{i n}}$ & 0.05 \\
\hline$O H^{* t A u}-H_{2} O * t A u$ & 0.05 \\
\hline $\mathrm{H}_{2} \mathrm{O} * t A u-\mathrm{H}_{2} \mathrm{O} * t A u$ & 0.05 \\
\hline $\mathrm{O}^{* t C}-\mathrm{H}_{2} \mathrm{O}^{* t M o}$ & 0.17 \\
\hline $\mathrm{O}^{* t M o_{i n}}-\mathrm{H}_{2} \mathrm{O}^{* t A u}$ & 0.04 \\
\hline $\mathrm{O}^{* t C_{i n}}-\mathrm{H}_{2} \mathrm{O}^{* t M o_{i n}}$ & 0.17 \\
\hline$C O^{* t C}-O^{* t M o}$ & 0.34 \\
\hline$C O^{* t C_{\text {in }}}-O^{* t A u}$ & 0.22 \\
\hline$C O^{* t C}-O H^{* *}(t C, t M o)$ & 0.28 \\
\hline$H C O^{* *}(t C, t M o)-O H^{* *}(t C, t M o)$ & 0.28 \\
\hline $\mathrm{CO}^{* t C_{\text {in }}}-\mathrm{OH} * t M o_{i n}$ & 0.23 \\
\hline$C O^{* t A u}-O H^{* t A u}$ & 0.23 \\
\hline$C O^{* t C_{\text {in }}}-O H^{* *}(t C, t M o)$ & 0.25 \\
\hline$C O^{* t C}-O H^{* t M o_{i n}}$ & 0.25 \\
\hline 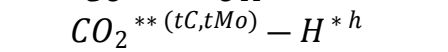 & 0.01 \\
\hline$C \mathrm{O}_{2}^{* *\left(t C_{i n}, t M o_{i n}\right)}-H^{* h_{i n}}$ & 0.01 \\
\hline 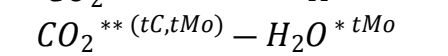 & 0.10 \\
\hline $\mathrm{CO}_{2}{ }^{* *\left(t C_{i n} t M o_{i n}\right)}-\mathrm{H}_{2} \mathrm{O}^{* t M o_{i n}}$ & 0.43 \\
\hline $\mathrm{CO}_{2}^{* *\left(t C_{i n} t M o_{i n}\right)}-\mathrm{H}_{2} \mathrm{O}^{* t A u}$ & 0.11 \\
\hline 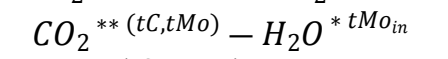 & 0.26 \\
\hline $\mathrm{CO}_{2}{ }^{* *\left(t C_{i n} t M o_{\text {in }}\right)}-\mathrm{H}_{2} \mathrm{O}^{* t M o}$ & 0.26 \\
\hline $\mathrm{CO}_{2}^{* *\left(t C, t M o_{i n}\right)}-\mathrm{H}_{2} \mathrm{O}^{* t M o}$ & 0.26 \\
\hline $\mathrm{CO}_{2}{ }^{* *}\left(t C_{i n} t \mathrm{Mo}\right)-\mathrm{H}_{2} \mathrm{O}^{* t M o_{i n}}$ & 0.26 \\
\hline$H C O^{* *(t C, t M o)}-O^{* t M o}$ & 0.06 \\
\hline$H C O^{* *(t C, t M o)}-O^{* t C}$ & 0.06 \\
\hline$C O^{* t C}-C O * t M o$ & 0.73 \\
\hline$H C O^{* *}(t C, t M o)-C O^{* t M o}$ & 0.73 \\
\hline$C O^{* t C}-C O^{* t C}$ & 0.62 \\
\hline$H C O^{* *}(t C, t M o)-H C O^{* *}(t C, t M o)$ & 0.73 \\
\hline$C O^{* t C}-H C O^{* *}(t C, t M o)$ & 0.62 \\
\hline
\end{tabular}




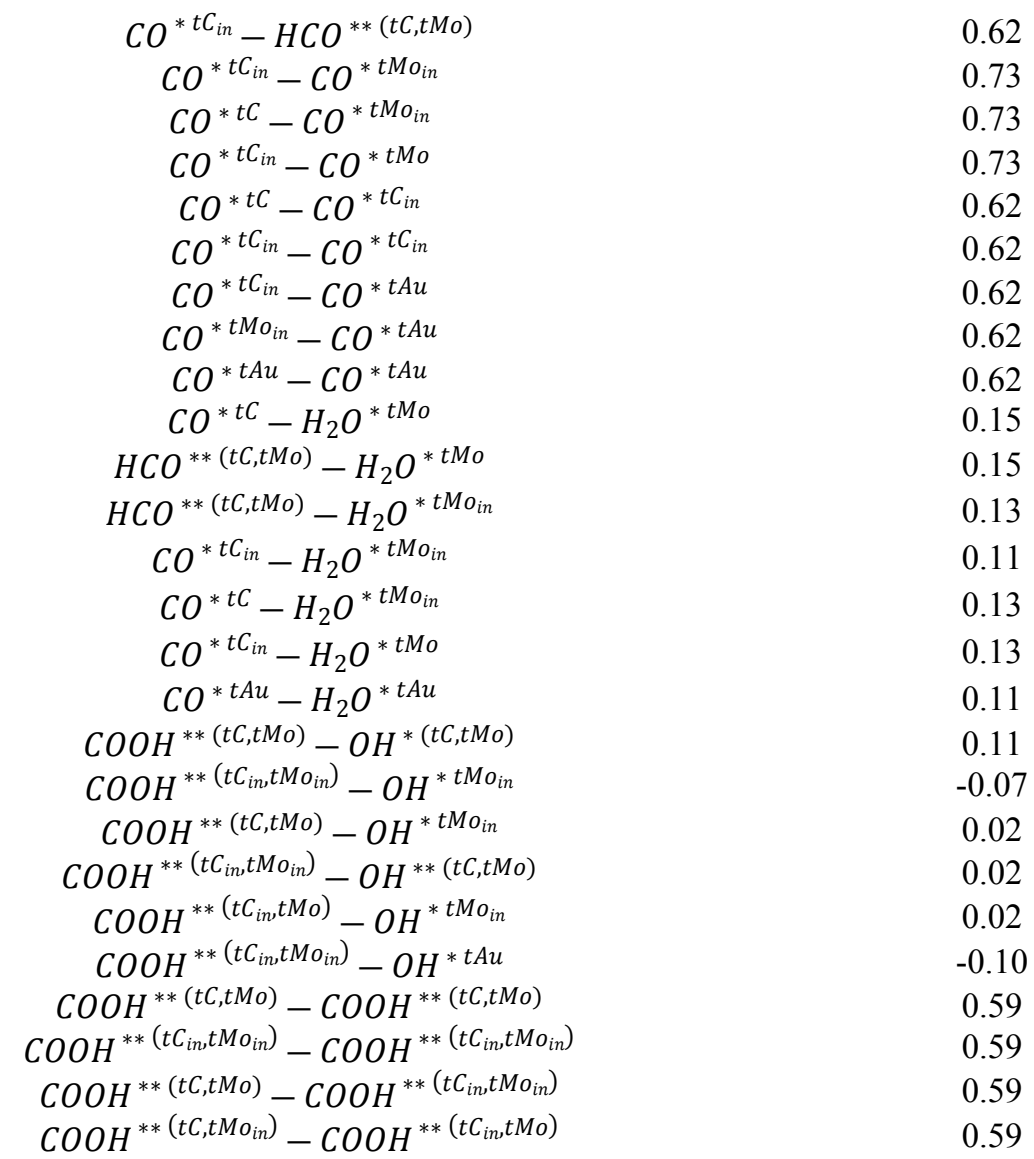

Table S5. Total number of kMC steps, lattice sites, integrated kMC time, total CPU time, and total number of $\mathrm{H}_{2}$ molecules produced per CPU day corresponding to the $\mathrm{kMC}$ simulations performed on the three studied systems at different reaction temperatures. All kMC simulations have been run on the same machine (Intel(R) Xeon(R) E5 - $46200 @ 2.20 \mathrm{GHz})$ using two cores.

\begin{tabular}{lccclccc}
\multicolumn{1}{c}{ System } & $\mathrm{T}(\mathrm{K})$ & $\begin{array}{c}\mathrm{kMC} \\
\text { steps }\end{array}$ & $\begin{array}{c}\text { Lattice } \\
\text { sites }\end{array}$ & $\begin{array}{c}\mathrm{H}_{2} \text { molecules } \\
\text { produced (total) }\end{array}$ & $\begin{array}{c}\text { Integrated } \\
\mathrm{kMC} \\
\text { time (s) }\end{array}$ & $\begin{array}{c}\mathrm{CPU} \\
\text { time } \\
(\mathrm{d})\end{array}$ & $\begin{array}{c}\mathrm{H}_{2} \text { molecules } \\
\text { produced per } \\
\text { CPU day }\end{array}$ \\
\hline $\mathrm{Au}(0.15 \mathrm{ML}) / \mathrm{MoC}$ & 410 & $5 \times 10^{8}$ & 432 & 120876 & 20.2 & 22.0 & 5494 \\
$\mathrm{Au}(0.15 \mathrm{ML}) / \mathrm{MoC}$ & 425 & $5 \times 10^{8}$ & 432 & 185883 & 14.2 & 21.9 & 8587 \\
$\mathrm{Au}(0.15 \mathrm{ML}) / \mathrm{MoC}$ & 435 & $3 \times 10^{8}$ & 432 & 146664 & 6.9 & 13.5 & 10864 \\
$\mathrm{Au}(0.15 \mathrm{ML}) / \mathrm{MoC}$ & 450 & $2 \times 10^{8}$ & 432 & 137975 & 3.2 & 9.2 & 14997 \\
$\mathrm{Au}(0.15 \mathrm{ML}) / \mathrm{MoC}$ & 465 & $2 \times 10^{8}$ & 432 & 176321 & 2.4 & 8.9 & 19811 \\
$\mathrm{Clean} \mathrm{MoC}$ & 465 & $2 \times 10^{8}$ & 200 & 74438 & 56.2 & 7.3 & 10197 \\
$\mathrm{Au}(0.25 \mathrm{ML}) / \mathrm{MoC}$ & 465 & $1 \times 10^{8}$ & 288 & 108658 & 6.4 & 2.3 & 47242 \\
\hline
\end{tabular}




\section{Supporting References}

${ }^{1}$ Lausche, A. C.; Medford, A. J.; Khan, T. S.; Xu, Y.; Bligaard, T.; Abild-Pedersen, F.; Nørskov, J. K.; Studt, F. On the Effect of Coverage-Dependent Adsorbate-Adsorbate Interactions for CO Methanation on Transition Metal Surfaces. J. Catal. 2013, 307, 275-282.

${ }^{2}$ Hammer, B. Coverage Dependence of $\mathrm{N}_{2}$ Dissociation at an $\mathrm{N}, \mathrm{O}$, or $\mathrm{H}$ Precovered $\mathrm{Ru}(0001)$ Surface Investigated with Density Functional Theory. Phys. Rev. B, 2001, 63, 205423.

${ }^{3}$ Groß, A. Coverage Effect in the Adsorption of $\mathrm{H}_{2}$ on $\mathrm{Pd}(100)$ Studied by $\mathrm{Ab}$ Initio Molecular Dynamics Simulations. J. Chem. Phys. 2011, 135, 174707.

${ }^{4}$ Mhadeshwar, A. B.; Kitchin, J. R.; Barteau, M. A.; Vlachos, D. G. The Role of Adsorbate-Adsorbate Interactions in the Rate Controlling Step and the Most Abundant Reaction Intermediate of $\mathrm{NH}_{3}$ Decomposition on Ru. Catal. Lett. 2004, 96, 13-22.

${ }^{5}$ Schmidt, D. J.; Chen, W.; Wolverton, C.; Schneider, W. F. Performance of Cluster Expansions of Coverage-Dependent Adsorption of Atomic Oxygen on $\mathrm{Pt}(111)$. J. Chem. Theory Comput., 2012, 8, 264-273.

${ }^{6}$ Miller, S. D.; Kitchin, J. R. Uncertainty and Figure Selection for DFT Based Cluster Expansions for Oxygen Adsorption on Au and Pt (111) Surfaces, Molecular Simulation, 2009, 35, 920-927.

${ }^{7}$ Posada-Pérez, S.; Gutiérrez, R. A.; Zuo, Z.; Ramírez, P. J.; Viñes, F.; Liu, P.; Illas, F.; Rodriguez, J. A. Highly Active $\mathrm{Au} / \delta-\mathrm{MoC}$ and $\mathrm{Au} / \beta-\mathrm{Mo}_{2} \mathrm{C}$ Catalysts for the Low-Temperature Water Gas Shift Reaction: Effects of the Carbide Metal/Carbon Ratio on the Catalyst Performance. Catalysis Science \& Technology 2017, 7, 5332-5342.

${ }^{8}$ Kresse, G.; Furthmüller, Efficient Iterative Schemes for Ab Initio Total-Energy Calculations Using a Plane-Wave Basis Set. Phys. Rev. B: 1996, 54, 11169.

${ }^{9}$ Perdew, J. P.; Burke, K.; Ernzerhof, M. Generalized Gradient Approximation Made Simple. Phys. Rev. Lett. 1996, 77, 3865-3868.

${ }^{10}$ Monkhorst, H. J.; Pack, J. D. Special Points for Brillouin-Zone Integrations. Phys. Rev. B 1976, 13, 5188-5192.

${ }^{11}$ Salciccioli, M.; Stamatakis, M.; Caratzoulas, S; Vlachos, D. G. A Review of Multiscale Modeling of Metal-Catalyzed Reactions: Mechanism Development for Complexity and Emergent Behavior. Che. Eng. Sci. 2011, 66, 4319-4355.

12 Mhadeshwar, A. B.; Wang, H.; Vlachos, D. G. Thermodynamic Consistency in Microkinetic Development of Surface Reaction Mechanisms. J. Phys. Chem. B 2003, 107, 12721-12733. 
${ }^{13}$ Su, Y.-Q.; Wang, Y.; Liu, J.-X.; Filot, I.; Alexopoulos, K.; Zhang, L.; Muravev, V.; Zijlstra, B.; Vlachos, D.; Hensen, E. Theoretical Approach to Predict the Stability of Supported Single-Atom Catalysts. ACS Catal. 2019, 9, 3289-3297.

${ }^{14}$ Stamatakis, M.; Vlachos, D. G. A Graph-Theoretical Kinetic Monte Carlo Framework for onLattice Chemical Kinetics. J. Chem. Phys. 2011, 134, 214115.

${ }^{15}$ Stamatakis, M.; Vlachos, D. G. Unraveling the Complexity of Catalytic Reactions via Kinetic Monte Carlo Simulation: Current Status and Frontiers. ACS Catal. 2012, 2, 2648-2663.

16 Nielsen, J.; d'Avezac, M.; Hetherington, J.; Stamatakis, M. Parallel Kinetic Monte Carlo Simulation Framework Incorporating Accurate Models of Adsorbate Lateral Interactions. J. Chem. Phys. 2013, 139, 224706.

${ }^{17}$ Marcinkowski, M. D.; Darby, M. T.; Liu, J.; Wimble, J. M.; Lucci, F. R.; Lee, S.; Michaelides, A.; Flytzani-Stephanopoulos, M.; Stamatakis, M.; Sykes, E. C. H. Pt/Cu Single-Atom Alloys as CokeResistant Catalysts for Efficient C-H Activation. Nature Chemistry 2018, 10, 325-332

${ }^{18}$ Prats, H.; Gamallo, P.; Illas F.; Sayós R. Comparing the Catalytic Activity of the Water Gas Shift Reaction on $\mathrm{Cu}(321)$ and $\mathrm{Cu}(111)$ Surfaces: Step Sites do not Always Enhance the Overall Reactivity.

J. Catal. 2016, 342, 75-83

19 Jansen, A.P.J.; An Introduction to Kinetic Monte Carlo Simulations of Surface Reactions. Lecture Notes in Physics, vol. 856, Springer-Verlag, Heidelberg, Germany, 2012.

${ }^{20}$ Laidler, K.J.; Chemical Kinetics, Harper \& Row Publishers, New York, USA, 1987.

${ }^{21}$ Nørskov, J. K.; Studt, F.; Abild-Pedersen, F.; Bligaard, T. Fundamental Concepts in Heterogeneous Catalysis, John Wiley \& Sons, Inc., 2014, ISBN: 978-1-118-88895-7.

${ }^{22}$ Getman, R. B.; Schneider, W. F. DFT-Based Coverage-Dependent Model of Pt-Catalyzed NO Oxidation. ChemCatChem 2010, 2, 1450-1460.

${ }^{23}$ Reuter, K.; Scheffler, M. First-Principles Kinetic Monte Carlo Simulations for Heterogeneous Catalysis: Application to the $\mathrm{CO}$ Oxidation at $\mathrm{RuO}_{2}(110)$. Phys. Rev. B 2006, 73, 045433.

${ }^{24}$ Chatterjee, A.; Voter, A. F. Accurate Acceleration of Kinetic Monte Carlo Simulations Through the Modification of Rate Constants, J. Chem. Phys., 2010, 132, 194101

${ }^{25}$ Dybeck, E. C.; Plaisance C. P.; Neurock, M. Generalized Temporal Acceleration Scheme for Kinetic Monte Carlo Simulations of Surface Catalytic Processes by Scaling the Rates of Fast Reactions, J. Chem. Theory Comput., 2017, 13, 1525-1538

${ }^{26}$ Yang, L.; Karim A.; Muckerman, J. T.; Density Functional Kinetic Monte Carlo Simulation of Water-Gas Shift Reaction on Cu/ZnO, J. Phys. Chem. C, 2013, 117, 3414-3425 
${ }^{27}$ Prats, H.; Álvarez, L.; Illas F.; Sayós, R. Kinetic Monte Carlo Simulations of the Water Gas Shift Reaction on $\mathrm{Cu}(111)$ From Density Functional Theory Based Calculations, J. Catal., 2016, 333, $217-$ 226

${ }^{28}$ Piccinin S.; Stamatakis, M. CO oxidation on Pd(111): A First-Principles-Based Kinetic Monte Carlo Study, ACS Catal., 2014, 4, 2143-2152

${ }^{29}$ Campbell, C. T.; The Degree of Rate Control: A Powerful Tool for Catalysis Research, ACS Catal., 2017, 7, 2770-2779. 